\title{
Impact-Evaluation of Baby Friendly Hospital Initiative: Case Study of Bassa LGA, Plateau State, Nigeria
}

\author{
Ogundeko TO. ${ }^{1}$, Obisesan OA. ${ }^{2}$, Ramyil MS. ${ }^{3}$, Adu OB. ${ }^{4}$, Akande T. ${ }^{5}$, \\ Toma B. ${ }^{6}$ \\ ${ }^{I}$ Department of Pharmacology and Therapeutics, College of Health Sciences, Bingham University, Jos, Nigeria. \\ ${ }^{2}$ Department of Haematology, Jos University Teaching Hospital, Jos, Nigeria. \\ ${ }^{3}$ Department of Medical Microbiology, College of Health Sciences, Bingham University, Jos, Nigeria. \\ ${ }^{4}$ Department of Biochemistry, Lagos State University, Ojo, Lagos, Nigeria. \\ ${ }^{5}$ Department of Chemical Pathology, College of Health Sciences, Bingham University, Jos, Nigeria. \\ ${ }^{6}$ Department of Paediatrics, University of Jos, Jos University Teaching Hospital, Jos, Nigeria.
}

\begin{abstract}
Study aimed to evaluate the impact of impact of BFHI on the world, especially at the grassroots, through Level of awareness, Influence and Effect. A total of 450 women were studied between the months of March and November 2010 in Bassa LGA in Plateau State, Nigeria. Relatively high level mere-awareness of $B F H I$ X(23.5); $S D$ (0.036), opinion about effect on lactating mothers $\bar{X}(82.8) ; S D(0.36)$ and willingness to practice and campaign $\bar{X}$ (54.6); $S D$ (0.143) respectively are positive indicators, despite strong negative factors on idea about BFHI duration X (19.9); SD (1.2).

However, relatively high level of awareness of BFHI has little influence and thus, commensurate little effect on the women. The fact that the third world countries still see BFHI and EBF practice as an idea of the developed world confirms ineffective communication as a major impediment to appreciable positive effect.
\end{abstract}

Keyword: BFHI, Awareness, Impact, Evaluation, Promotion, Bassa.

\section{Introduction}

Owing to the fact that many life-saving programs in the world surfer the problems of evaluation, reevaluation, sustenance, consolidation amongst others, there is urgent need to address these adverse situation in order to save more lives, reduce wastage and consolidate good breastfeeding practices. Among the most important challenges that we face in mobilizing the scientific and social forces and resources to meet the health and development needs of women and children as we enter the $21^{\text {st }}$ century is that of ensuring that infants and young children get a healthy nutritive start in life. The first step to that start in life is breastfeeding [1].

Child survival is very essential for the sustenance of the total population of a country. The urban dwellers enjoy basic amenities including; nearness to information, while their rural counterpart enjoy little or none of these modern facilities. The increasing problem of feeding the growing population in developing countries has been a persistent problem. With evidence of gross inadequate availability and consumption of protein foods, coupled with population and urbanization, these nutritional problems will remain if efforts are not made towards finding more available and cheaper sources of protein [2].

Babies should be fed exclusively on human breast milk to enable them develop normally, both physically and mentally. It contained all a child needs for a normal growth, therefore unless medically instructed give new born infant no food or drink other than breast milk [3].

Breast milk is the preferred feeding for new born; infant formula is intended to replace of supplement breast milk when feeding is not possible or insufficient or when mothers elect not to breast feed. There is a wealth of information on the benefits of breastfeeding, especially exclusive breastfeeding (EBF), for the mother and infant [4]. Breastfeeding is widely practiced in Nigeria but EBF rates in various studies have been extremely low $(2 \%)$ and $(0 \%)[5],[6]$.

The level of awareness of BFHI is still very low as a result of much emphasis on more modern means of dissemination of information without considering such means as peculiar to meeting the needs of rural dwellers or people at the grass root [7].

Some of the major factors identified which influence EBF in some communities in the country included attitudes of health workers and policies of health facilities on breastfeeding [8], [9]-[11].The idea of keeping expressed breast milk for the infant while the mother is away is good but may be hazardous in this environment where hygiene is poor [12]. An important conclusion from the LAC-NHS study was that because women stayed for a very short period of time after hospital discharge, it is therefore very important to substantially strengthen the efficacy of community-based BF peer counseling as related to facilitating BF promotion at the community level [13]. 


\subsection{Aims and objectives of Study} and Effect.

This work seeks to evaluate the impact of BFHI on the world through Level of awareness, Influence

The result obtained from Bassa LGA of Plateau State, Nigeria will be used as yardstick to conclude on same in the other parts of the world, especially the Third world countries.

\section{Geographical Background and People of Bassa}

Bassa is a local Government Area in the North of Plateau State, Nigeria, bordering Kaduna and Bauchi States. Its Headquarters are in the town of Bassa at $9^{0} 56^{\prime} 00^{\prime \prime} \mathrm{N}, 8^{0} 44^{\prime} 00^{\prime \prime} \mathrm{E}$. It has an area of $1,743 \mathrm{Km} 2$ and a population of 186,859 according to the 2006 census. It enjoys the presence of the $3^{\text {rd }}$ Armoured Division of the Nigerian Army. The Local Government is made up of nine districts with major tribes - Pengana, Irigwe and Rukuba. The languages are native dialects common to the people of the area, English and Hausa. Most of the people are engaged in farming, trading and carpentry [14].

\subsection{Agricultural Produce}

Maize, Millet, Beni-seed, Potatoes, Cassava, Pepper, Beans, Rice, Yam, Wheat and groundnuts which are produced in commercial quantities[14].

\subsection{Mineral Resources}

Tin, Zircon, Columbite, Feldspar and Granite.

\subsection{Tourism}

Rockset [14].

Bassa parades unique Rukuba Rock, Jebbu Hills, Dutsen Kura Hills, Ngalachua Rock, and Assari

\section{Methods}

A 14-point close ended structured questionnaire based on three themes: Level of awareness, Influence and Effect was administered by 2 of the authors and supported by 5 volunteers who speak the native languages viz: 2 community health students, a nurse and 2 non - health workers, between the months of March and November 2010 in Bassa Local Government Area in Plateau State, Nigeria. A total of 450 women were studied, which include mothers from different classes of life.

Data was analyzed with statistical program for social science (SPSS) and Minitab also at $95 \%(\alpha=$ $0.05)$ confidence.

\section{Results:}

A total of 450 women were studied. Having analyzed the data collected, the following results were obtained:

Age distribution: $18-24$ years (22\%), 25-34 years (41\%) and 35-44 years $(37 \%)$. Mean and SD $=31.34$; (0.047) - Fig. 1, Marital Status: Married (85\%), Single (10\%) and Divorced (5\%). Mean and SD $=29.1 ;(0.13)-$ Fig.2, Tribe Distribution: Rukuba (27\%), Pengana (19\%), Irigwe (19\%) and Others (35\%) - Fig.3, Literacy Status about BFHI: Literate (39\%) and Non- Literate (61\%). Mean and SD $=26 ;(0.16)-$ Fig.4, Level of BFHI awareness: Aware $(70 \%)$ and Not Aware (30\%). Mean and SD = 23.5; (0.036) - Fig.5, Idea about BFHI duration: At least three months (48\%), at least six months (36\%) and at least nine months (36\%). Mean and SD $=19.9 ;(1.2)$ - Fig.6, Source of awareness of BFHI: is a strong factor with the mean19.9 and SD (1.2) while the percentage distribution of sources of BFHI awareness is: through Ante-natal Clinic (24\%), Friends (9\%), Family /Relations (13\%), Media (Magazines/Newspapers/Television/Radio and Posters (33\%) and never heard $(21 \%)$. Mean and $\mathrm{SD}=19.9$; (1.2) - Fig.7, Knowledge of someone that has tried BFHI: Yes (22\%), No (78\%). Mean and SD $=23.8 ;(0.43)$ Fig.8, Opinion of relations BFHI: Negative (56\%), Positive (26\%), do not care $(18 \%)$. Mean and SD $=15.8 ;(0.43)$ - Fig.9, Opinion about effect of BHFI on the Child: Negative $(90 \%)$ and Positive (10\%) effect on the child. Mean and SD = 35.8; SD (0.43) - Fig.10, BFHI effect on the lactating mother: Positive (68\%) and Negative (32\%). Mean and $\mathrm{SD}=82.8$; (0.36) - Fig.11, Exclusive Breastfeeding (EBF) Practice: Those already practicing or intending to practice EBF were $(55 \%)$ and those who are not practicing or not ready to do such $(45 \%)$. Mean and $\mathrm{SD}=54.6$; $(0.143)$ - Fig. 12, Readiness to campaign for BFHI scheme: Ready (62\%) and Not ready (38\%). Mean and $\mathrm{SD}=46.2 ;(0.68)-$ Fig. 13, Preferred languages of communication for BFHI campaign: Rukuba (17\%), Pengana (13\%), Irigwe (18\%), Hausa (16\%), English $(22 \%)$ and other languages $(14 \%)$, while Mean and $\mathrm{SD}=34.6 ; 0.03$ - Fig. 14, 


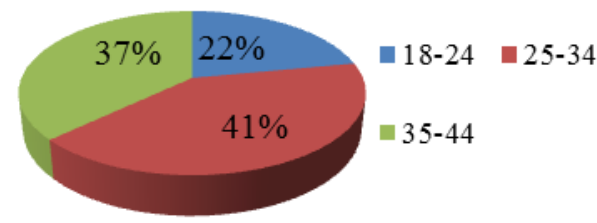

Fig 1: Age Distribution

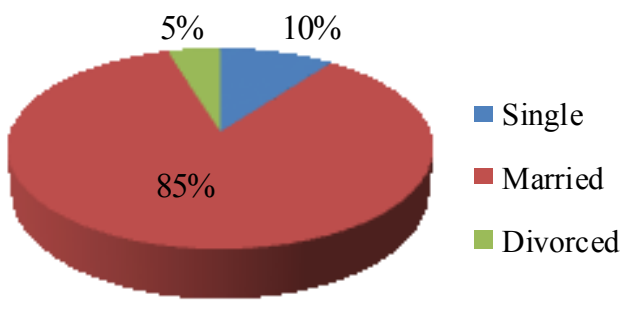

Fig 2:Marital Status

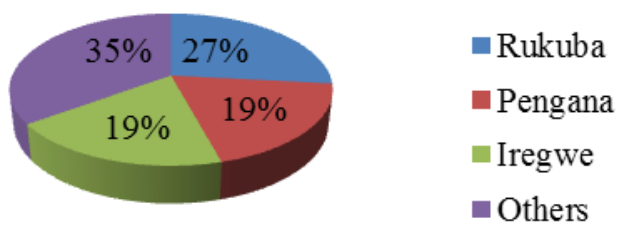

Fig 3:Tribe Distribution

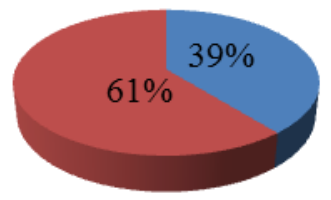

- Literate

Fig 4: Litracy Status

- Non-literate

\section{Fig 5: BFHI Awareness}

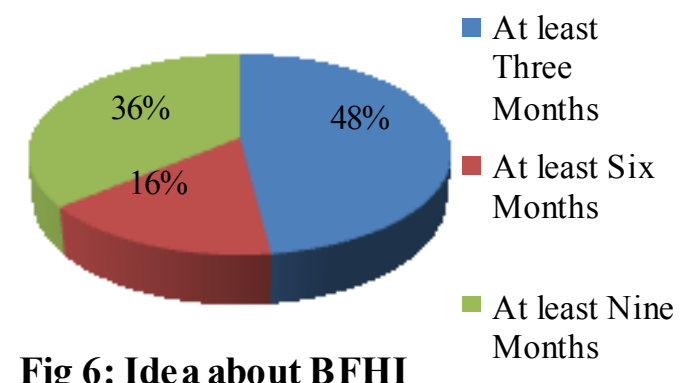

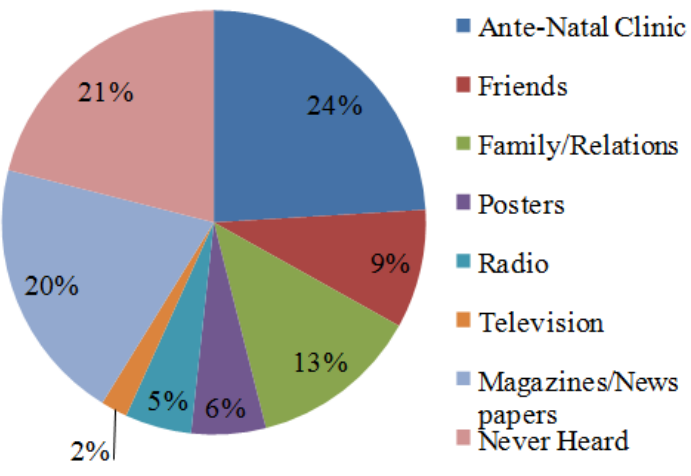

Fig 7: Source of Awareness of BFHI

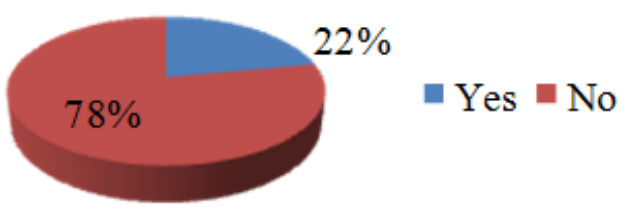

Fig 8: Knowledge of someone that has tried EBF

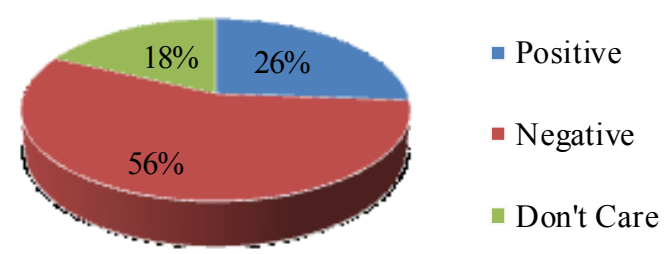

Fig 9: Relations' Opinion about BFHI

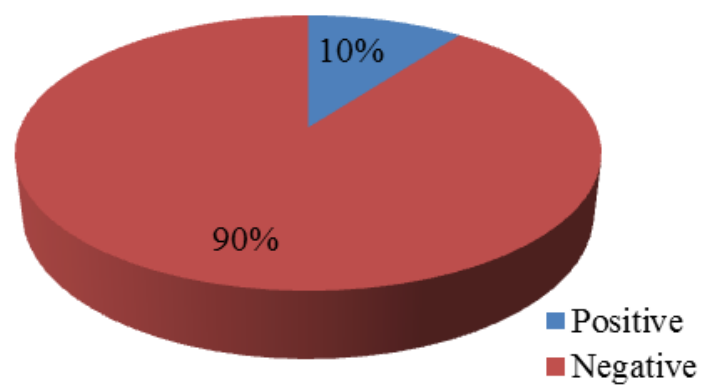

Fig. 10: Opinion About BFHI Effec on the Child

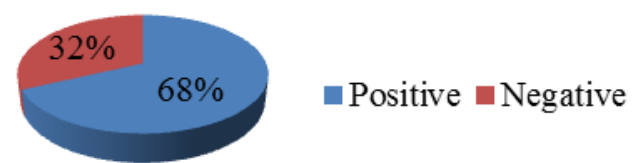

Fig. 11: Idea About BFHI Effect on Lactating Mother duration 


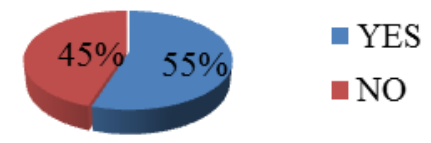

Fig. 12: Presently

Practicing/Intending to Practice

EBF

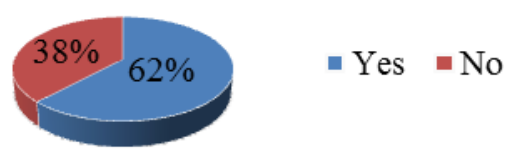

Fig.13: Readiness to
Campaign BFHI

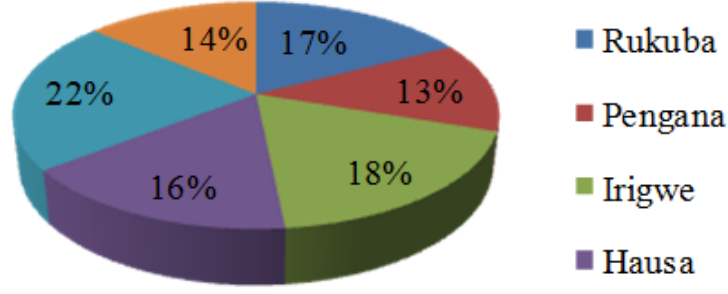

Fig. 14 (a): Prefered Language for English BFHI Campaign

Fig. 14 (b): Prefered Language for BFHI Campaign Rukuba

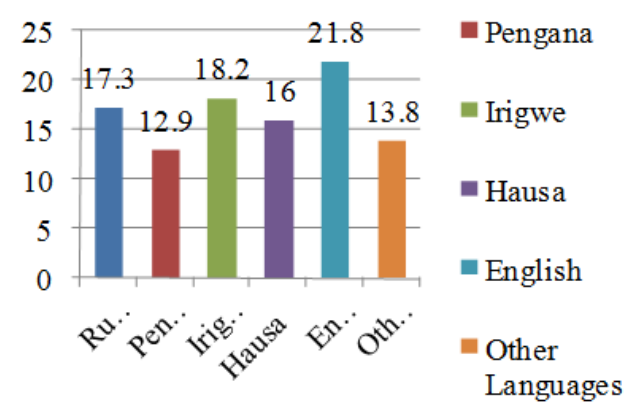

\section{Discussion}

It is a fact that people from various communities have different ideologies and beliefs about breast feeding practices (BFP), such which is also attached to their backgrounds, emotions, behaviors, desires and beliefs.

Mothers between ages 25-34 (41\%) and 35-44 (37\%) constituted 78\% of the total number of population studied showed appreciable population of experienced mothers in breastfeeding practices. High level of awareness of BFHI (70\%) observed with Mean and SD $(23.5 ; 0.036)$. Sources of awareness, which is a strong factor, played a significant role in attesting to the fact that the Ante-Natal Clinic (24\%) is still the surest place to campaign BFHI and EBF. Evidence from developed and developing countries indicates that the BFHI has had a direct impact on breastfeeding rates at the hospital level [15], [16]-[18]. Despite high level of awareness and strong indication that breastfeeding has positive effect on the lactating mother $(68 \%)$, there are palpable indications that mothers still have reservations about exclusive breastfeeding practice for at least first six months of life, as $22 \%$ known to have tried EBF, $56 \%$ negative opinion from relations about same and $90 \%$ believe that EBF would have negative effect on the child. This buttresses the findings in earlier studies: Awareness level of people at the grassroots level on BFHI is very low due to inadequate campaign language [7].

Intending to practice EBF (55\%) and Readiness to campaign BFHI $(62 \%)$ are strong indications that there could be better involvement of women in the BFHI scheme. For this reason, we feel that the observed trends may represent a conservative estimate of the BFHI's potential [19]. Problems relating this may not be farfetched from the decline in international support for third world countries; however, the effectiveness of programs such as the BFHI has been questioned and there has been a reduction in international support for this programe (Labbok M,personal communication from global theory carried out in 2006,[20].The preferred language for campaign for BFHI is that of the natives (Irigwe, Pengana, Rukuba) and Hausa which is a general language in the geopolitical zone, all constituting $78 \%$. This is a salient factor in reaching out to the grassroots.

Pressures from relations, as well as, environmental, behavioral and emotional challenges remain factors that BFHI has to contend with. The persistence of the practice of early introduction of supplementary feeds may suggest that there are strong cultural issues attached to breast feeding practices which need to be addressed [21].

\subsection{Conclusion}

Laxity and decline in the promotion of Baby Friendly Hospital Initiative (BFHI) and Exclusive Breastfeeding (EBF) calls for urgent attention. One thing is just to be aware; another is to be well informed, guided and adequate implementation. Relatively high level of awareness of BFHI has little influence and thus, commensurate little effect on the women in Bassa Local Government Area, Plateau State Nigeria. In other words, level of awareness of BFHI is still low. 
Another major challenge facing BFHI is ineffective communication. The way and manner by which BFHI and EBF practice is understood by many is a function of how information is exchanged between individual through system of symbols, sign and behavior. The fact that the third world countries still see BFHI and EBF practice as an idea of the developed world confirms ineffective communication as a major impediment to appreciable effect so far.

\subsection{Recommendations}

Properly guided communication strategies to educate all stake holders, including men in our society through the mass media with the use of the language of the locals while pictorial illustration of locals are suggested as BFHI campaign tools. These suggested tools should also be harnessed through the Women Breastfeeding Groups (WBG) and Health Workers. Therefore mode of communicating (campaigning) BFHI should not be taken with levity.

Sequel to the various factors found to contribute to the low level of awareness: Misconception about the effect of Exclusive Breast Feeding (EBF) for at least six months right immediately after delivery of the child, Wrong Language of Communication, Inadequate use of the Media, negative attitude of family/relations, prompt and deliberate steps to address the aforementioned is suggested.

\section{Conflict of Interest}

No conflicting interest

\section{Acknowledgements}

Our profound gratitude goes to the Chairman Hon. Amil Anko and Director Primary Healthcare Department of Bassa Local Government Council for giving permission to carry out this project.

We sincerely acknowledge the support and contributions of Associate Prof. Christian O. Isichie, Associate Prof. O.F Asalu, Dr. G.I Toma, Dr Moses Chingle, Rev. Emmanuel Didam Mr. Munkini Dimka, Miss. Rifkatu Bulus, Mrs Racheal Ike, Mr Joshua Ameh, Mr Segun Adeniyi, Mr, Davou Fom, and Miss Stella Onyejiuwa.

\section{References}

[1] Okolo SN, Ogbonna C: Knowledge, attitude and practice of health workers in Keffi local government hospitals regarding BabyFriendly Hospital Initiative (BFHI) practices. European J. Clinical Nutrition. 56, 2002, 326-337. DOI:10.1038/sj/ejcn/1601331.

[2] Makinde MA, Elemo BO, Arukwe U, Pellett P: Ukwa seed (Treculia Africana) protein: Chemical evaluation of the protein quality. J Agric Food Chem. Vol 3: 1, 1985, pp 70-72..

[3] Osunkeye S: Ten things to know about breastfeeding. Sunday Concord Newspaper,August 1996, pp. 10.

[4] Savage-King F: Helping mothers to breastfeed. African Med. And Med Research Foundation, 2nd edn, 1992, 24-28.

[5] Federal Office of Statistics: Nigeria Demographic and Health Survey. DHS IRD/ Macro International Inc. 1990

[6] Okolo SN, Adewunmi YB, Okonji MC: The current breastfeeding Knowledge, attitude and practices of mothers in five rural communities in the savannah region of Nigeria. J. Trop Paediatr, 45:1999, 323-326.

[7] Ogundeko T.O: The Factors influencing the Baby Friendly Hospital Initiative (BFHI) and Family Planning Schemes on the rural areas using Monguno Local govt. in Borno state as a case study. NYSC. CDS. Project, 1996

[8] Ekele BA, Ahmed H: Exclusive breastfeeding, Hospital or Home practice. Nig. Med. Pract, 33: 1997, 62

[9] Federal Ministry of Health: National Breastfeeding Policy. Nairobi: Federal Govt. of Nigeria. 1990

[10] Malami SA: Knowledge, attitude and practice of EBF among nursing mothers in Akwa Ibom State of Nigeria. Nig. Med. Pract, 30: 1995, 2-3.

[11] Ogbonna C, Okolo SN, Eziogu A: Factors influencing exclusive breasfeeding in Jos, Plateau State, Nigeria. West Afr. J. Med., 2000,107

[12] Infant and Toddler Feeding Practices in the Baby Friendly Initiative (BFI) Era in Ilesa, Nigeria. The Internet J. Nutrition and Welness.Vol.1:2, 2005

[13] Rafael Perez-Escamilla: Evidence Based Breast-Feeding Promotion: The Baby-Friendly Hospital Initiative1. The J. Nutr.vol.137: 2007, 484-487.

[14] http://www.plateaustate.gov.ng (2008). Accessed $21^{\text {st }}$ june 2014.

[15] Rosenberg KD, Stull JD, Adler MR, Kasehagen LJ, Crivelli-Kovach A: Impact of hospital policies on breastfeeding outcomes: Breastfeed Med. 3(2): 2008, 110-116. PubMed Abstract / Publisher Full Text. Accessed $23^{\text {rd }}$ June, 2014.

[16] Kramer MS, Chalmers B, Hodnett ED, Sevkovskaya Z, Dzikovich I, Shapiro S, Collet JP, Vanilovich I, Mezen I, Ducruet T, Shishko G, Zubovich V, uik D, Gluchanina E, Dombrovskiy V, Ustinovitch A, Kot T, Bogdanovich N, Ovchinikova L, Helsing E: PROBIT Study Group: Promotion of Breastfeeding Intervention Trail (PROBIT): arandomized trail in the Republic of Belarus. JAMA 285(4): 2001, 413-420. PubMed Abstract / Publisher Full Text. Accessed $23^{\text {rd }}$ June, 2014.

[17] Merten S, Dratva J, Ackermann-Liebrich U: Do Baby-friendly hospital influence breastfeeding duration on anational level? Pediatrics 116(5): 2005, e702-708. PubMed Abstract / Publisher Full Text. Accessed 23 ${ }^{\text {rd }}$ June, 2014.

[18] DiGirolamo AM, Grummer-Strawn LM, Fein SB: Effect of maternity-care practices on breastfeeding. Pediatrics 122 (suppl 2): 2008, S43-49. PubMed Abstract / Publisher Full Text. Accessed 23 ${ }^{\text {rd }}$ June, 2014.

[19] Sheryl W Abrahams, Miriam H Labbok. Exploring theimpact of the Baby-Friendly Hospital Initiative on trends in exclusive breastfeeding. Int. Breastfeeding J. 4:11, 2009, doi;10.1186/1746-4358-4-11.

[20] UNICEF 1990-2005: Celebrating the innocenti on the Protection, Priority Action for Infant and Young Child Feeding. $2^{\text {nd }}$ edition. UNICEF Innocenti Research Centre, Florence, Italy, 2006.

[21] Ighogboja IS, Odumodu CU, Olanrewaju RS. Breastfeeding pattern in Jos, Nigeria before Baby Friendly Hospital Initiative. J. Trop Pediatr. 42: 1996:178-9. 